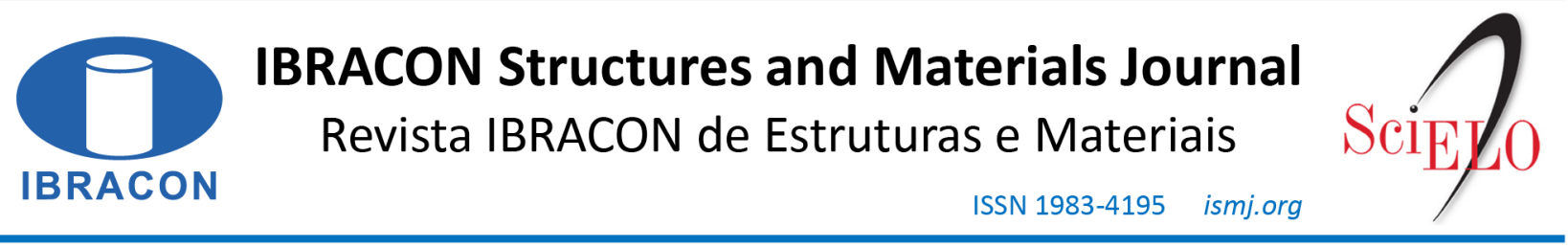

ORIGINAL ARTICLE

\title{
Resistant bending moment to lateral-torsional buckling of continuous steel and concrete composite beams with transverse stiffeners
}

\section{Momento fletor resistente à flambagem lateral com distorção de vigas mistas contínuas de aço e concreto com enrijecedores transversais}

\author{
Janaina Pena Soares de Oliveira ${ }^{\mathrm{a}}$ \\ João Victor Fragoso Dias ${ }^{\mathrm{b}}$ (D) \\ Ricardo Hallal Fakury ${ }^{\mathrm{b}}$ (D) \\ Adenilcia Fernanda Grobério Calenzanic

\begin{abstract}
${ }^{a}$ Instituto Federal do Espírito Santo - IFES, Departamento de Engenharia Civil, Vitória, ES, Brasil

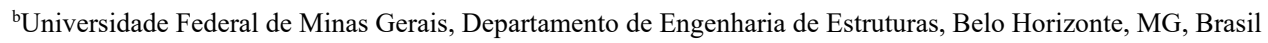 \\ ${ }^{\mathrm{c}}$ Universidade Federal do Espírito Santo, Departamento de Engenharia Civil, Vitória, ES, Brasil
}

Received 23 April 2020

Accepted 25 November 2020

\begin{abstract}
In this paper, a numerical analysis using the finite element method, employing the commercial code Ansys, is performed to evaluate the influence of transverse stiffeners welded to the web of the steel profile on the lateral stiffness and resistant bending moment of continuous steel and concrete composite beams subjected to lateral-torsional buckling (LTB). The developed numerical model was validated by comparison with the results of tests performed by another researcher. Subsequently, a parametric analysis was carried out for beams with two and three spans, varying the spacing between the stiffeners. Finally, based on the analysis performed, it was concluded that the transverse stiffeners can significantly increase the lateral stiffness and the resistant moment of continuous composite beams. A calculation procedure to obtain this moment is proposed, having as reference the prescriptions of the Brazilian standard ABNT NBR 8800:2008.
\end{abstract}

Keywords: continuous steel and concrete composite beams, lateral-torsional buckling, transverse stiffeners, resistant bending moment, lateral stiffness.

Resumo: Neste artigo, uma análise numérica usando método dos elementos finitos, com apoio do software Ansys, é realizada para avaliar a influência de enrijecedores transversais soldados à alma do perfil de aço na rigidez lateral e no momento fletor resistente de vigas mistas contínuas de aço e concreto à flambagem lateral com distorção (FLD). O modelo numérico desenvolvido foi validado por meio de comparação com os resultados de ensaios realizados por outro pesquisador. Na sequência, foi feita uma análise paramétrica, para vigas com dois e três vãos, variando-se o espaçamento entre os enrijecedores. Finalmente, com base nas análises realizadas, conclui-se que os enrijecedores transversais podem aumentar significativamente a rigidez lateral e o momento resistente de vigas mistas contínuas e um procedimento de cálculo para se obter esse momento, tendo como referência as prescrições da norma brasileira ABNT NBR 8800:2008, é proposto.

Palavras-chave: vigas mistas contínuas de aço e concreto, flambagem lateral com distorção, enrijecedor transversal, momento fletor resistente, rigidez lateral.

How to cite: J. P. S. Oliveira, J. V. F. Dias, R. H. Fakury, and A. F. G. Calenzani, "Resistant bending moment to lateral-torsional buckling of continuous steel and concrete composite beams with transverse stiffeners," Rev. IBRACON Estrut. Mater., vol. 14, no. 4, e14412, 2021, https://doi.org/10.1590/S1983-41952021000400012

Corresponding author: Janaina Pena Soares de Oliveira. E-mail: janaina.pena@ifes.edu.br

Financial support: Conselho Nacional de Desenvolvimento Científico e Tecnológico (CNPq), Coordenação de Aperfeiçoamento de Pessoal de Nível Superior (CAPES) e Fundação de Amparo à Pesquisa do Estado de Minas Gerais (FAPEMIG).

Conflict of interest: Nothing to declare. 


\section{INTRODUCTION}

\subsection{Lateral-torsional buckling of continuous steel and concrete composite beams}

The most used continuous steel and concrete composite beams are those in which the steel profile, almost always with I section, keeps its continuity on the internal supports, normally consisting of columns of the building's structure.

In these beams, the bottom flange is subjected to compression in the hogging moment region (near the internal supports) and, consequently, may suffer lateral instability, moving in the direction of the minor axis inertia of the steel profile. This flange is subjected to a lateral translation, $\delta$, which is necessarily accompanied by a rotation, $\theta$, since the web needs to bend laterally (distort) for the displacement to occur, according to Figure 1a, resulting in an ultimate limit state known as lateral-torsional buckling (LTB). The occurrence of this phenomenon is facilitated by the concrete slab's bending and the deformation of the connection of this slab with the top flange of the steel profile (shear connection). According to Johnson [1], the displacements $\delta$ and $\theta$ create a half-wave on each side of the internal supports, with maximum values located in the cross sections between two and three times the height of the steel profile $(d)$ apart from these supports, as shown in Figure 1b. It is important to emphasize that at the internal supports, the bottom flange of steel profile must be laterally constrained.

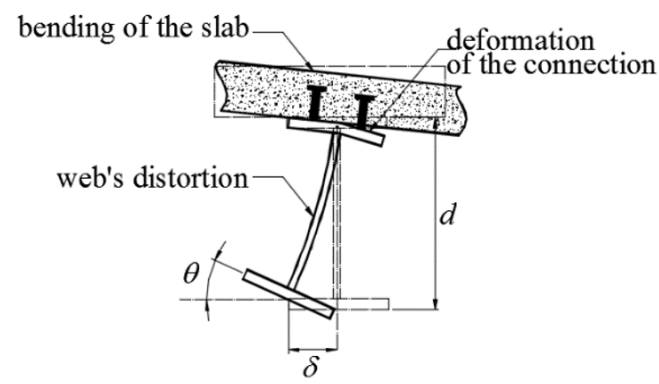

a) Cross section displacements

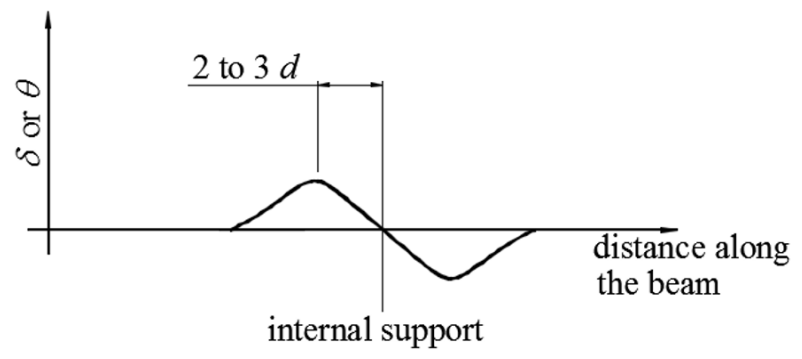

b) Bottom flange displacements along the beam [1]

Figure 1. Lateral-torsional buckling

\subsection{Inverted "U"- frame mechanism}

The Brazilian standard [2] provides an approximate procedure to verify LTB, similar to the European standard [3], which consists of determining the elastic critical moment $\left(M_{c r}\right)$ as an initial step to obtain the resistant bending moment. This critical moment is obtained by considering the inverted " $U$ "- frame mechanism, formed by the concrete slab supported by two or more parallel steel beams. This mechanism is different from the usual "T", which consists of a single steel beam under the concrete slab. The use of the inverted "U"- frame mechanism better represents the boundary conditions that are imposed by the floor system to the steel beam.

In the scientific literature and highlight by Calenzani [4], two types of inverted " $U$ "- frame mechanisms are described, the continuous and discrete mechanisms. In the continuous " $U$ "- frame mechanism, the steel and concrete composite beam has transverse stiffeners only at the internal supports. In this type of mechanism, the restriction to lateral translation of the compressed flange is provided only by the concrete slab and by the unstiffened web of the steel profile. In the discrete "U"- frame mechanism, there are transverse stiffeners welded to the web of the steel profile regularly spaced throughout the hogging moment region, which contribute to the distortional rigidity.

\subsection{Calculation of the resistant moment to LTB according to standards}

The calculation methods of the Brazilian [2] and European [3] standards for determining the LTB resistant moment of continuous composite beams are approximate, considering only the situation of the continuous inverted "U"- frame mechanism, therefore with transverse stiffeners only at the internal supports, and it consists of the following steps:

a) Determination of elastic critical moment at the internal support of the relevant span where the hogging bending moment is greatest. The European standard [3] does not provide an equation for this determination, while the Brazilian standard [2] adopts the formulation proposed by Roik et al. [5], given by: 
$M_{c r}=\frac{C_{\text {dist }} \alpha_{g}}{L} \sqrt{\left(G_{a} J+k_{r} \frac{L^{2}}{\pi^{2}}\right) E_{a} I_{a f, y}}$

in which $E_{a}$ and $G_{a}$ are elasticity and shear modulus of the steel profile, respectively, $J$ is the torsion constant of the profile, $I_{a f, y}$ is the second moment of area of the bottom flange of I profile about the axis passing through the web's medium plane ( $y$ axis). The $\alpha_{g}$ factor is associated with the geometry of the cross section of the composite beam and $C_{\text {dist }}$ is a coefficient that considers the bending moment distribution along the member's length $L$. Also, $k_{r}$ is the rotational stiffness per unit length of the beam expressed by the following equation:

$k_{r}=\frac{k_{1}+k_{2}}{k_{1} k_{2}}$

in which $k_{1}$ is the flexural stiffness of the cracked concrete slab in the direction transverse to the I profile and $k_{2}$ is the flexural stiffness of the steel web.

The flexural stiffness of the concrete slab is obtained as:

$k_{1}=\alpha \frac{(E I)_{2}}{a}$

with $\alpha$ being a coefficient that depends on the beam's position in the floor system ( $\alpha=2$ for an edge beam and $\alpha=3$ for an inner beam - for an inner beam in a floor with four or more similar beams, $\alpha=4$ may be used). $(E I)_{2}$ is the cracked flexural stiffness per unit width of the concrete slab and $a$ is the spacing between the parallel beams of the "U"- frame mechanism.

The steel web's flexural stiffness can be taken as:

$k_{2}=\frac{E_{a} t_{w}^{3}}{4 h_{0}\left(1-v^{2}\right)}$

in which $t_{w}$ is the thickness of the web of the steel profile, $h_{0}$ is the distance between the geometric centers of the two flanges of the steel profile and $v$ is the Poisson's ratio for the structural steel.

b) Determination of a slenderness parameter, given by:

$\lambda_{\text {dist }}=\sqrt{\frac{M_{R k}^{-}}{M_{c r}}}$

where $M_{R k}^{-}$is the nominal resistant bending moment of the beam's cross section at hogging bending moment region, constituted by the steel profile and the longitudinal reinforcements.

c) Determination of the reduction factor $\chi_{\text {dist }}$ from the value of $\lambda_{\text {dist }}$ with the use of a resistant curve.

d) Determination of the nominal resistant moment of the composite beam, from the value of $\chi_{\text {dist }}$, through the expression:

$M_{\text {dist }, R k}^{-}=\chi_{\text {dist }} M_{R k}^{-}$

In fact, in step d), both standards already directly prescribe the determination of the design resistant moment, by the equation: 
$M_{d i s t, R d}^{-}=\chi_{d i s t} M_{R d}^{-}$

where $M_{R d}^{-}$is the design resistant moment of the cross section in the hogging bending moment region, determined in a similar way to $M_{R k}^{-}$with the application of partial coefficients to the yield strengths of the steel profile and the longitudinal reinforcement of the slab. However, in this paper, to facilitate comparative analyses and evaluation, the values of the nominal resistant moments were always considered.

Although the procedures of the two standards are similar, besides already mentioned the fact that the European standard [3] does not provide an equation to determine the elastic critical moment, there are also two differences between them that can lead to very different results of the value of the resistant moment to LTB:

1) the resistant curve used to obtain $\chi_{\text {dist }}$ from the value of $\lambda_{\text {dist }}$ is not the same;

2) the Brazilian standard [2] is only applicable to compact steel sections, with the nominal resistant moment to LTB reaching the plastic moment of the composite cross section, while the European standard [3] is applicable to sections up to Class 3, which are those that can present local instability in an inelastic regime, situation in which the maximum nominal resistant moment is the one corresponding to the beginning of yield of the composite cross section.

The second inequality brings up an inconsistency, that deserves further studies, because steel cross sections are classified differently in the two standards. Thus, it is very common, that, depending on the web's slenderness, the cross section may be classified as compact by the Brazilian standard [2], with the resistant moment reaching the plastic moment, and as Class 3 by the European standard [3], situation in which the resistant moment is limited to that of the beginning of yield.

\subsection{Previous studies}

The phenomenon of lateral-torsional buckling in continuous composite beams has been studied by several researchers since the 1980s, when Bradford and Trahair [6], Svensson [7] and Goltermann and Svensson [8] addressed the issue of determination of the elastic critical moment. In 1990, Roik et al. [5] proposed an equation to obtain this moment which is still adopted by the current Brazilian standard [2], as stated in the previous subsection. Some further investigation has been made to improve the equation proposed by Roik et al. [5], for example, Hanswille [9], Amaral et al. [10], Dias et al. [11] and Oliveira [12].

In all proposed methods for the determination of $M_{c r}$, it is necessary obtain the rotational stiffness of the inverted "U"- frame mechanism of the composite beam, represented by $k_{r}$. To determine these values of stiffness, experimental or numerical analysis may be performed. However, there is in a literature a practical alternative, with very reliable results, which is to consider it as resulting from the serial association between the flexural stiffness of the slab $\left(k_{1}\right)$, the transverse flexural stiffness of the steel profile's web $\left(k_{2}\right)$ and the stiffness of the shear connection $\left(k_{3}\right)$. This option is adopted by the Brazilian [2] and European [3] standards, neglecting the influence of $k_{3}$, since this stiffness is usually very high when compared to the other two. Some studies have been carried out in order to propose equations for the determination of these stiffnesses and analyze their relative influence in the final value of the rotational stiffness $k_{r}$, such as Chen [13], Calenzani et al. [14], Chen and Wang [15] and Dietrich et al. [16].

In addition to Brazilian [2] and European [3] standards, which adopt the continuous inverted "U"- frame mechanism as the basis for obtaining the resistant moment to LTB, the Australian [17], [18] and American [19], [20] standard calculation procedures are presented in the literature. These last two standards, however, deal with the phenomenon in a simpler way, based on the conventional theory of lateral-torsional buckling of steel profiles. Rossi et al. [21] compared their numerical results with those of the four mentioned standards and highlighted that the Australian [17], [18] and American [19], [20] standards lead to more conservative results. According Rossi et al. [21], the use of conventional theory of lateral-torsional with only the influence of the steel profile provides inaccurate results since the model is based on inappropriate hypotheses. A procedure for calculating the resistant moment to LTB highlighted by Rossi et al. [21] is proposed by Zhou and Yan [22], that doesn't need the initial determination of the elastic critical moment $\left(M_{c r}\right)$. This procedure provides good results, however, is valid only for composite beams subjected to uniform hogging moment.

In continuous composite beams, it can be necessary to use transverse stiffeners to elevate the value of shear strength of the web due to the possibility of instability. These stiffeners, as they also restrict the web distortion, provide additional lateral restraint to bottom flange of the steel profile, which causes an elevation of the elastic critical and LTB resistant moments. In order to evaluate the transverse stiffeners influence in LTB, Chen [13] tested two full-scale prototypes, 
one with composite beams composing a continuous "U"- frame mechanism (prototype U4) and another with distributed stiffeners along the hogging moment regions, forming in this case the discrete "U"- frame mechanism (prototype U5).

Prototype U4 was composed of two welded beams (U4A and U4B), with double stiffeners welded to the web only at the supports. To prevent lateral and vertical movements between the beams, without restricting rotation in relation to the vertical axis, an internal bracing formed by angles was added in the support section (Figure 2).
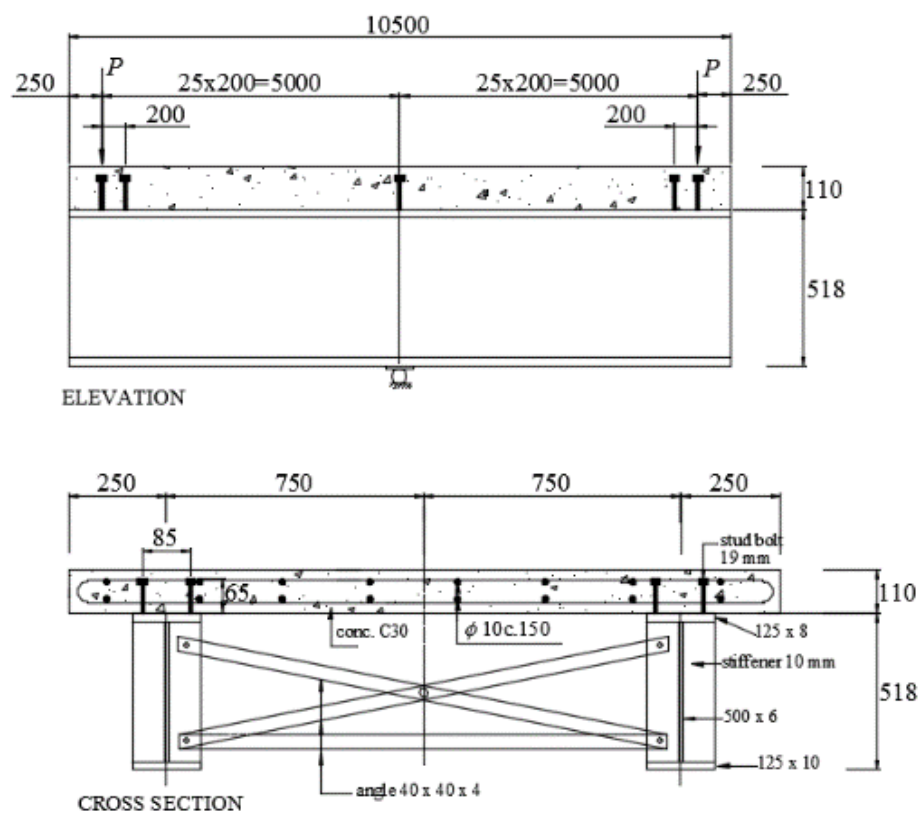

Figure 2. Elevation and cross section of prototype U4 at the support (dimensions in millimeter) [13].

Prototype U5 also was made of two welded beams (U5A and U5B), with cross sections identical to those of U4A and U4B. Chen [13] considered two types of stiffeners in prototype U5: in half of the length of the beam, double stiffeners were adopted (on both sides of the steel profile), spaced every $1,200 \mathrm{~mm}$; in the other half, the stiffeners were welded only to one side of the steel profile, spaced every $600 \mathrm{~mm}$.

Two lateral instability modes were found in the tests by Chen [13]. In prototype U4, without stiffeners, a mode that extended for most of the hogging bending moment region was observed, characterized by an approximate sinusoidal shape, symmetrical in relation to the central section. In prototype U5, however, the lateral instability modes were concentrated close to the support region.

A numerical study to analyze the structural behavior in hogging bending moment of continuous steel and concrete composite beams with transverse stiffeners welded to web of the steel profile was performed by Chen and Wang [15]. In this study, finite element models were implemented using the Ansys software.

Elastic buckling analyses and nonlinear buckling analyses were performed. In the buckling analyses, numerical models were adopted consisting of a simply supported steel beam without transverse stiffeners or by a steel beam with stiffeners, both with the influence of the slab simulated by spring elements with rotational stiffness $k_{1}$ and rigid supports to prevent lateral displacement of the top flange. The models were submitted to uniform hogging moment through the application of a moment at the ends of the beams. It was found that the use of stiffeners in the steel profile's web significantly reduced the wavelength of the buckling mode of the beam and, consequently, raised the elastic critical moment to LTB. Through the parametric studies carried out by the authors Chen and Wang [15], it was possible to verify that this elevation was proportional to the reduction of the spacing between stiffeners and with the increase in the thickness of their plates.

Chen and Wang [15] proposed a calculation procedure for determining the resistant moment to LTB of steel and concrete composite beams with transverse stiffeners at the profile's web. In this procedure, the authors [15] recommend the adoption of the equation of $M_{c r}$ proposed by Roik et al. [5], that is, Equation 1 presented in this paper, and the 
calculation steps prescribed by the European standard [3] (see subsection 1.3), using the following equation to obtain the rotational stiffness of the stiffened web:

$$
k_{2, e}=\frac{1}{4} \frac{E_{a}}{1-v_{a}^{2}} \frac{t_{w}^{3}}{h_{0}}+\frac{E_{a}}{4} \frac{\left(2 b_{s}+t_{w}\right)^{3} t_{s}}{h_{0} L_{u}}
$$

in which $b_{s}$ and $t_{s}$ are the width and thickness of the stiffeners, respectively, and $L_{u}$ is the spacing between the stiffeners.

\subsection{About this paper}

In this paper, the objective is to evaluate the influence of transverse stiffeners welded to web of the steel profile in the lateral stiffness and in the value of resistant bending moment of steel and concrete composite beams to lateraltorsional buckling (LTB). It is also an objective of the study to verify the possibility of using the calculation procedure proposed by Chen and Wang [15] together with the Brazilian standard [2] instead of the European standard [3] to determine the resistant bending moment. Strictly speaking, this means using the prescriptions of the Brazilian standard [2], only replacing Equation 4 by Equation 8, since this standard already uses the equation proposed by Roik et al. [5], Equation 1, to determine the elastic critical moment.

To accomplish this objective, a finite element model of composite beams with transverse stiffeners welded to steel profile's web at hogging bending moment region was developed using the Ansys 17.0 software [23], in order to obtain the nominal resistant bending moment to lateral-torsional buckling. Then, this model was validated by comparison with tests results by Chen [13]. In sequence, a parametric analysis was performed for continuous composite beams with two or three spans, varying the spacing between the transverse stiffeners. Finally, the results obtained with the procedure of Chen and Wang [15] combined with the prescriptions of the Brazilian standard [2] were assessed by comparison with the results of the numerical analyses. In addition, as another assessment device, the results obtained with the procedure of Chen and Wang [15] combined with the prescriptions of the European standard [3] were also compared with those of the numerical analyses.

\section{FINITE ELEMENT MODELS}

\subsection{Model definition}

In the numerical study conducted in this paper, inner beams of inverted "U"- frame mechanisms, shown in Figure $3 \mathrm{a}$, were analyzed. There is symmetry on concrete slab in relation to the plane parallel to the web that passes through the semidistance between two adjacent beams. Thus, only one steel beam and half of the concrete slab on each side were simulated, with the adoption of appropriate boundary conditions in the cutting planes (free ends) of the slab (horizontal displacements, rotation about the horizontal axis and rotation about the vertical axis, represented by Uz, RotX and RotY, respectively, prevented), as illustrated in Figure $3 b$.

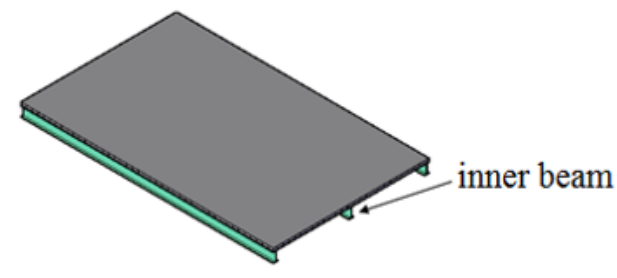

a) Inverted "U"- frame mechanism and inner beam

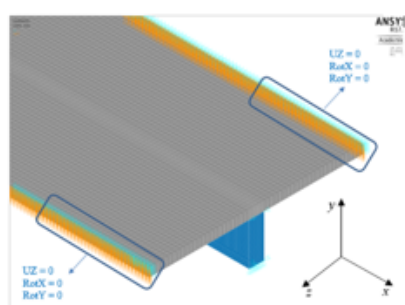

b) Boundary conditions at the free ends of the slab

Figure 3. Inverted "U"- frame mechanism analyzed in this paper. 
To assess the resistant bending moment to LTB of extreme spans, the numerical model was composed by two spans and three supports. For inner spans, however the composite beams were represented by a numerical model with three spans and four supports.

All nodes in the bottom flange of steel profile in the support sections of numerical models had translation in the global $y$ direction (vertical) restrained and the central node of that flange had the translation in the global $x$ direction (longitudinal) restrained, according to Figure 4. Moreover, to simulate the fork supports and prevent the rotation of cross section at the supports, the displacements in the $z$ direction (horizontal) were restrained at the extreme nodes of the top and bottom flanges of the steel profile. Transverse stiffeners were modeled on the cross sections at the supports, to eliminate any influence of local deformations.

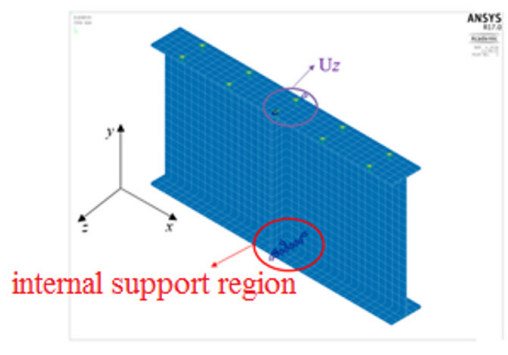

a) Internal support region

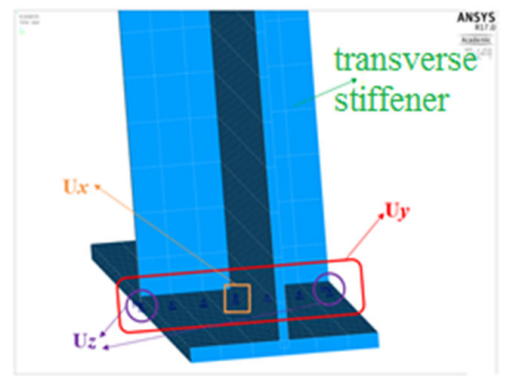

b) Composite beam support

Figure 4. Boundary conditions of numerical models.

The loading of extreme and inner spans of composite beams was applied through a uniformly distributed load per unit area in the upper slab face. For the extreme span of continuous composite beams, the same load was applied to each span of the beam. To analyze the inner span, the situation of constant bending moment diagram was adopted in the analyzed span (inner span), with equal distributed loads applied only to the end spans.

\subsection{Used elements}

As illustrated in Figure 5, the numerical models consisted of the steel profile and stiffeners, modeled with the shell element Shell181, a reinforced concrete slab, modeled with the solid element Solid65, and stud bolt shear connectors, modeled with the beam element Beam188. To simulate the interaction between the concrete slab and top flange of the steel profile, contact elements Conta173 and Targe 170 were used.

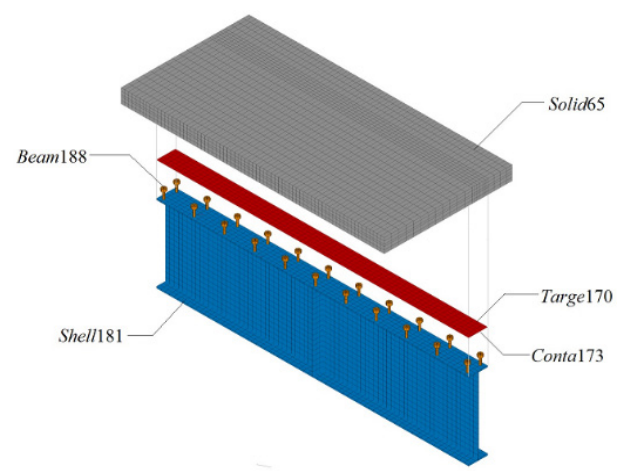

Figure 5. Types of elements adopted in numerical models.

The positive and negative reinforcements of the concrete slab were simulated in a dispersed way in the elements Solid65, defining the values of their area ratios in each coordinate axis direction. The positive reinforcement was positioned near bottom face of the slab, from one support to the other in all spans. The negative reinforcement was 
positioned near the upper slab face, centered on the internal supports with length equal to a quarter the sum of adjacent spans, in order to reach the inflection points of bending moment diagrams as described by the Brazilian standard [2]. This reinforcement also has, for each side, beyond the inflection points, an extension of $10 \%$ of the distance between these points, as a safety measure, and an additional extension, $l_{b}$, for anchoring purposes, as prescribed by the Brazilian standard [24].

\subsection{Constitutive relationships of materials}

The uniaxial behavior of the profile's steel, the transverse stiffeners and reinforcements was considered as bilinear elastoplastic, with a first straight until reaching the yield strength, $f_{y}$, with tangent modulus equal to steel modulus of elasticity, $E_{a}$, and a second straight line with a tangent modulus equal to $1 / 10,000$ of the modulus of elasticity, to avoid numerical convergence problems. Steel is assumed to follow the von Mises yield criterion, with isotropic hardening rule, applicable for ductile material analysis. The values adopted for the modulus of elasticity and Poisson's ratio are equal to $200,000 \mathrm{MPa}$ and 0.3 , respectively.

The behavior of concrete under uniaxial compression was modeled based on the stress-strain relationship of the European standard [25]. The Poisson's ratio adopted for concrete was 0.2. It is assumed that the concrete follows the failure criterion of Willam-Warnke, Solid65 element's standard criterion. According to European [25] and Brazilian [24] standards, the average tensile strength of the concrete can be obtained using the following equation:

$$
f_{c t m}=0,3 f_{c k}^{2 / 3}
$$

where $f_{c k}$ is the characteristic compressive strength of the concrete.

Initial convergence problems were observed due to concentrations of compression stresses in the concrete slab near the shear connectors. Considering that the behavior of the connection between the slab and the steel profile is not critical in the assessed problem (since there is full shear interaction) and that in hogging bending moment region, the tension behavior of the slab is of greater importance than the compression behavior, it was decided to disable crushing of the concrete in the numerical models of this study. Tests carried out showed that there are no relevant differences in the force-displacement curves of models with and without crushing, which were coincident in the analysis up to the failure point of solution convergence.

In this paper, the values suggested by Contamine et al. [26] were adopted for the shear transfer coefficients for open and closed cracks, equal to 0.6 and 0.9 , respectively.

\subsection{Mesh study and solution techniques}

To define the ideal element size, a mesh study was carried out with 64 numerical models with the same characteristics of the prototype tested by Chen [13], shown in Figure 2. For each model, the total number of elements, the critical LTB force, the percentage variation of this force between the results obtained in the current analysis (more refined mesh) and the previous (less refined mesh) were evaluated. It was concluded that the elements of the steel profile must have a maximum size equal to $30 \mathrm{~mm}$ and, those of the concrete slab, $60 \mathrm{~mm}$. These mesh sizes presented results with a relative difference of around $0.05 \%$ between two consecutive analysis.

In the numerical model developed in this study, nonlinear analysis with large displacements, considering the geometric imperfections from the manufacturing process and material imperfections resulting from residual stresses in the steel profile was performed. Material nonlinearity is considered by adopting different tensile and compressive strengths for the reinforced concrete and non-linear behavior of steel. Due to the contact between the slab and the top flange of the steel profile, there is also the status nonlinearity.

After determining all the nonlinearities of the numerical models, nonlinear analysis was performed considering the standard incremental-iterative procedure of Newton Raphson. The stiffness matrix adjustment technique was used to accelerate the solution convergence of the numerical model.

\subsection{Geometric imperfections and residual stresses}

In the validation step of the numerical model, the initial geometric imperfections measured by Chen [13] in prototypes U4 and U5 were adopted. For the consideration of geometric imperfections in the steel profile of parameterization models, a lateral displacement was applied to the nodes of bottom flange with maximum value equal 
to $80 \%$ of the manufacturing tolerance of the profile, as prescribed by European standard [27], located at a distance from the internal support corresponding to three times the height of the steel profile, with its value decreasing according to LTB mode. Figure 6a highlights the region where the geometric imperfection was applied in extreme span models and, Figure $6 \mathrm{~b}$, the region in which the imperfection was applied in the internal span models, with the acronym IMPMAX corresponding to the maximum imperfection applied in the numerical model.

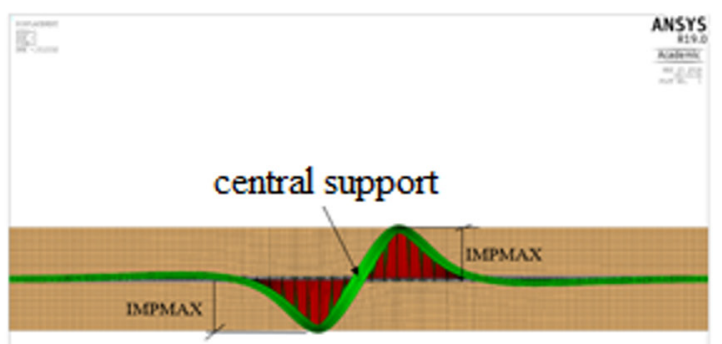

a) Extreme span models

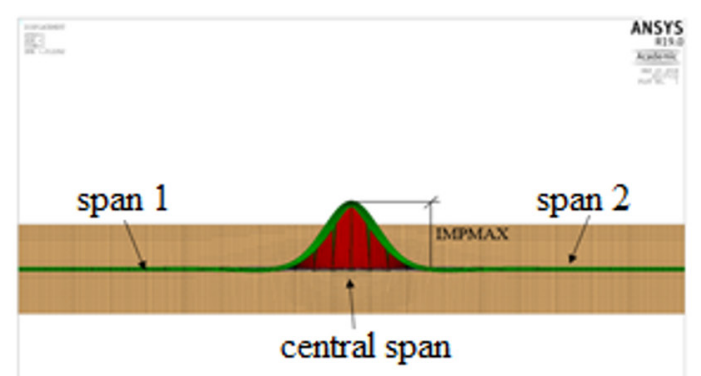

b) Inner span models

Figure 6. Geometric imperfection applied in parameterization models.

The residual stresses in steel profiles used in Chen's tests [13], which are welded with laminated edge plates, were not measured. Thus, in the numerical model for the validation of this paper, residual stresses were introduced in the nodes of the finite elements of the flanges and web of the steel profile, with the distribution presented in Figure 7a, considering linear variation in the web and flanges. The maximum tension adopted, equal to $30 \%$ of the yield strength of the steel, both in tension and compression, is prescribed by the Brazilian standard [2] for the design of steel beams.

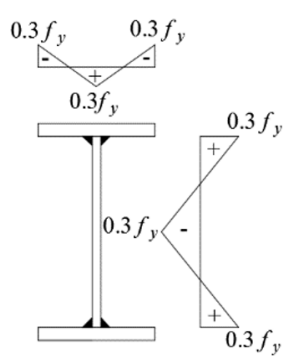

a) Linear distribution of rolled or welded steel profiles with laminated edge plates

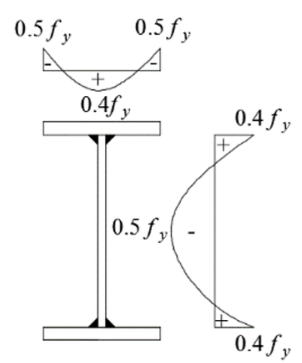

b) Non-linear distribution of rolled or welded steel profiles with laminated edge plates

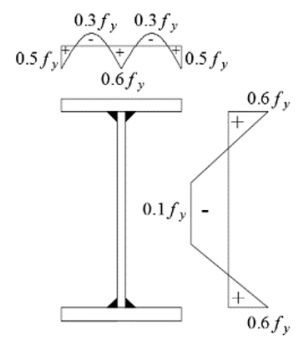

c) Distribution of welded steel profiles with blowtorch cut edges plates

Figure 7. Types of residual stress distributions analyzed.

Regarding the residual stress distribution of the parametric study models, an evaluation was carried out comparing the results of resistant bending moment to LTB obtained numerically, considering three types of residual stress distribution. One of them corresponds to the distribution adopted in the validation model presented in Figure 7a. The second also corresponds to the distribution of a laminated or welded profile with laminated edge plates, considering nonlinear distribution on the flanges and the web, similar to the distribution studied by Silva [28], presented in Figure 7b. Lastly, the distribution of a welded profile with blowtorch cut edges was considered (Figure 7c) with nonlinear distribution on flanges and linear with a uniform stretch in the web, also studied by Silva [28].

In the numerical models analyzed, a composite beam with two extremes spans of lengths equal to $15 \mathrm{~m}$ subjected to a uniformly distributed load of equal value was considered. A spacing between parallel beams, $a$, of $3 \mathrm{~m}$ was adopted. The slab was $120 \mathrm{~mm}$ high and negative reinforcements in both directions equal to $20 \mathrm{~cm}^{2} / \mathrm{m}$ were adopted. The positive reinforcement adopted in both directions corresponds to $9.5 \mathrm{~cm}^{2} / \mathrm{m}$. The rates adopted for these reinforcements are of 
the order of 2.5\%, and they are in the upper range of the limit recommended by the Brazilian standard [24] in order to facilitate the occurrence of LTB before reaching the plastic moment in the hogging bending moment region. The yield strength of steel profile, $f_{y}$, was assumed to be equal to $300 \mathrm{MPa}$. Table 1 describes the characteristics of the steel profile, in addition to the type of residual stress distribution adopted. The acronym DL corresponds to the distribution represented in Figure 7a, DNL to the distribution of Figure $7 \mathrm{~b}$ and DPS to the distribution of Figure 7c.

Table 1. Numerical models for residual stress analysis.

\begin{tabular}{cccccc}
\hline model & $\boldsymbol{d}(\mathbf{m m})$ & $\boldsymbol{b}_{\boldsymbol{f}}(\mathbf{m m})$ & $\boldsymbol{t}_{\boldsymbol{f}}(\mathbf{m m})$ & $\boldsymbol{t}_{\boldsymbol{w}}(\mathbf{m m})$ & Type of residual stress distribution \\
\hline TR1 & 800 & 200 & 16 & 12.5 & $\mathrm{DL}$ \\
\hline TR2 & 700 & 200 & 16 & 12.5 & $\mathrm{DL}$ \\
\hline TR3 & 600 & 200 & 16 & 12.5 & $\mathrm{DL}$ \\
\hline TR4 & 500 & 200 & 16 & 12.5 & $\mathrm{DL}$ \\
\hline TR5 & 400 & 200 & 16 & 12.5 & $\mathrm{DL}$ \\
\hline TR6 & 800 & 200 & 16 & 12.5 & DNL \\
\hline TR7 & 700 & 200 & 16 & 12.5 & DNL \\
\hline TR8 & 600 & 200 & 16 & 12.5 & DNL \\
\hline TR9 & 500 & 200 & 16 & 12.5 & DNL \\
\hline TR10 & 400 & 200 & 16 & 12.5 & DNL \\
\hline TR11 & 800 & 200 & 16 & 12.5 & DPS \\
\hline TR12 & 700 & 200 & 16 & 12.5 & DPS \\
\hline TR13 & 600 & 200 & 16 & 12.5 & DPS \\
\hline TR14 & 500 & 200 & 16 & 12.5 & DPS \\
\hline TR15 & 400 & 200 & 16 & 12.5 & DPS \\
\hline
\end{tabular}

The LTB resistant moment obtained numerically corresponds to the peak of the graph that relates the lateral displacement of the geometric center of bottom flange with the bending moment. Table 2 shows the obtained results, with $M_{R, D L}$ being the bending moment obtained numerically for models TR1 to TR5, $M_{R, D N L}$ the resistant moment of the models TR6 to TR10 and $M_{R, D P S}$ the resistant moment of the models TR11 to TR15. This table also presents the ratio between the resistant moment of models with residual stress distribution represented by the acronym DL as a function of the other residual stress distributions considered in this paper.

Table 2. Numerical results obtained for residual stress analysis.

\begin{tabular}{|c|c|c|c|c|c|c|c|}
\hline Model DL & Model DNL & Model DPS & $M_{R, D L}(\mathbf{k N} \cdot \mathbf{m})$ & $\begin{array}{l}M_{R, D N L} \\
(\mathbf{k N} \cdot \mathbf{m})\end{array}$ & $\begin{array}{c}M_{R, D P S} \\
(\mathbf{k N} \cdot \mathbf{m})\end{array}$ & $M_{R, D L} / M_{R, D N L}$ & $M_{R, D L} / M_{R, D P S}$ \\
\hline TR1 & TR6 & TR11 & 1,553 & 1,526 & 1,577 & 1.02 & 0.99 \\
\hline TR2 & TR7 & TR12 & 1,414 & 1,398 & 1,428 & 1.01 & 0.99 \\
\hline TR3 & TR8 & TR13 & 1,220 & 1,209 & 1,250 & 1.01 & 0.98 \\
\hline TR4 & TR9 & TR14 & 1,009 & 1,003 & 1,030 & 1.01 & 0.98 \\
\hline TR5 & TR10 & TR15 & 828 & 816 & 842 & 1.01 & 0.98 \\
\hline \multicolumn{6}{|c|}{ average } & 1.01 & 0.98 \\
\hline
\end{tabular}

Table 2 shows that the difference in resistant bending moment for each type of residual stress distribution corresponds to a maximum of $2 \%$. This demonstrates that the type of residual stress adopted in the parametric study has negligible influence on the value of the LTB resistant bending moment. Because of this, in the parametric study developed in this paper, the same residual stress distribution of the validation models was adopted, represented by Figure $7 \mathrm{a}$. 


\subsection{Results of the numerical validation models}

To validate the numerical model developed in this paper, the prototypes U4 and U5 of Chen's study [13], already described, were simulated, with the same materials characteristics, geometric properties and support and loading conditions reported by the author [13].

The values obtained with the numerical modeling of the two prototypes were compared with the values obtained in the tests performed by Chen [13]. Figure 8 shows a curve of the vertical displacement of the beam ends (ends of the cantilever) versus the moment in the supports of each model. It indicates that the resistant bending moment of the numerical simulation of the prototype U4 was equal to $320 \mathrm{kN} \cdot \mathrm{m}$, only $0.66 \%$ higher than Chen's result [13], of approximately $318 \mathrm{kN} \cdot \mathrm{m}$. For prototype U5, the maximum bending moment of the numerical simulation was equal to $438.57 \mathrm{kN} \cdot \mathrm{m}, 7 \%$ higher than Chen [13], of about $407 \mathrm{kN} \cdot \mathrm{m}$.

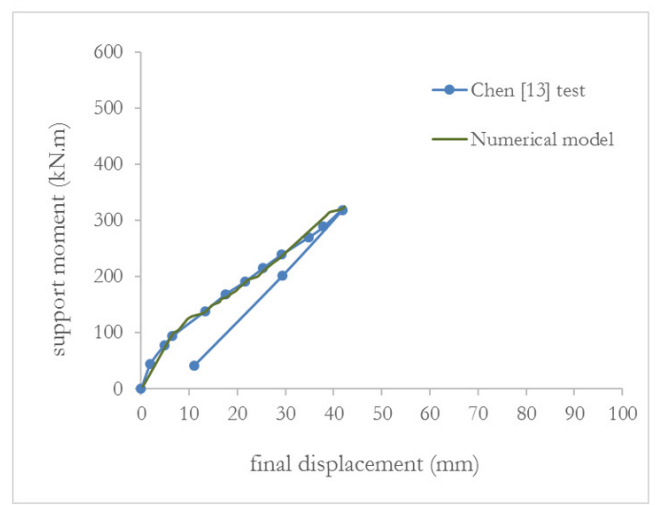

a) Prototype U4

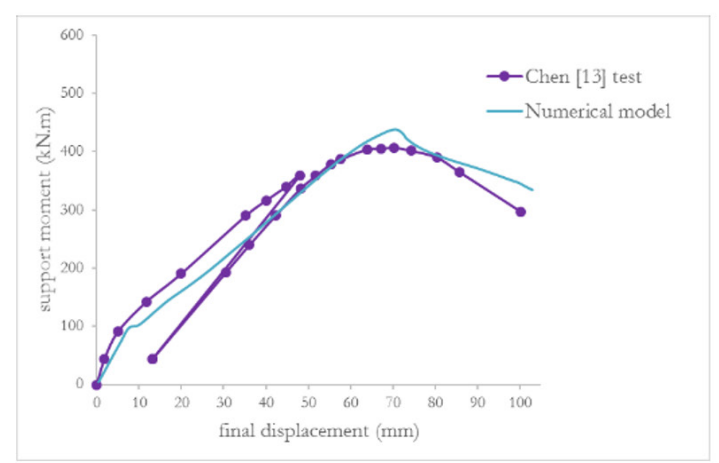

b) Prototype U5

Figure 8. Vertical displacement at the free end of the composite beam.

Another relevant comparison is that of lateral displacement of bottom flange of steel profile at the end of the test. As seen in Figure 9, the numerical results were close to Chen's experimental measurements [13].

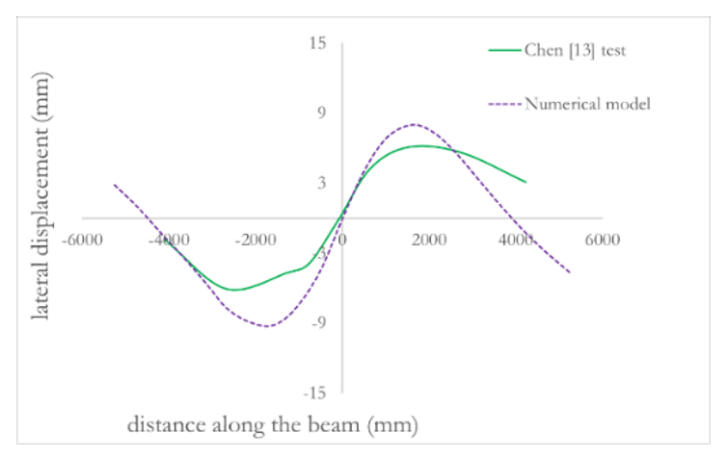

a) Prototype U4

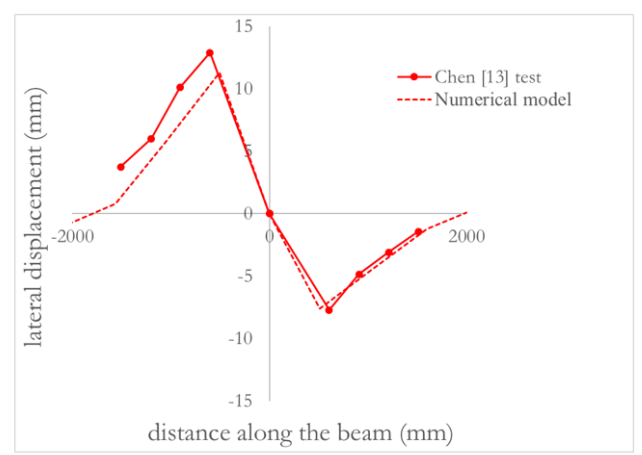

b) Prototype U5

Figure 9. Lateral displacement of the bottom flange of the steel profile.

Therefore, there is an acceptable agreement between the results of the numerical models developed in this paper and Chen's tests [13], both in terms of resistant moment and structural behavior. Thus, the numerical model developed is considered appropriate for the study of LTB in steel and concrete composite beams. 


\section{PARAMETRIC ANALYSIS}

\subsection{General considerations}

A parametric numerical analysis was performed to evaluate the LTB resistant bending moment of continuous steel and concrete composite beams with transverse stiffeners welded to the web of the steel profile. Figure 10 illustrates the cross section at the internal support of the numerical model adopted as standard in parameterization models. Regarding the spans, the value of $15 \mathrm{~m}$ was adopted as default, which corresponds to 25 times the height of the steel profile, a usual proportion in professional practice.

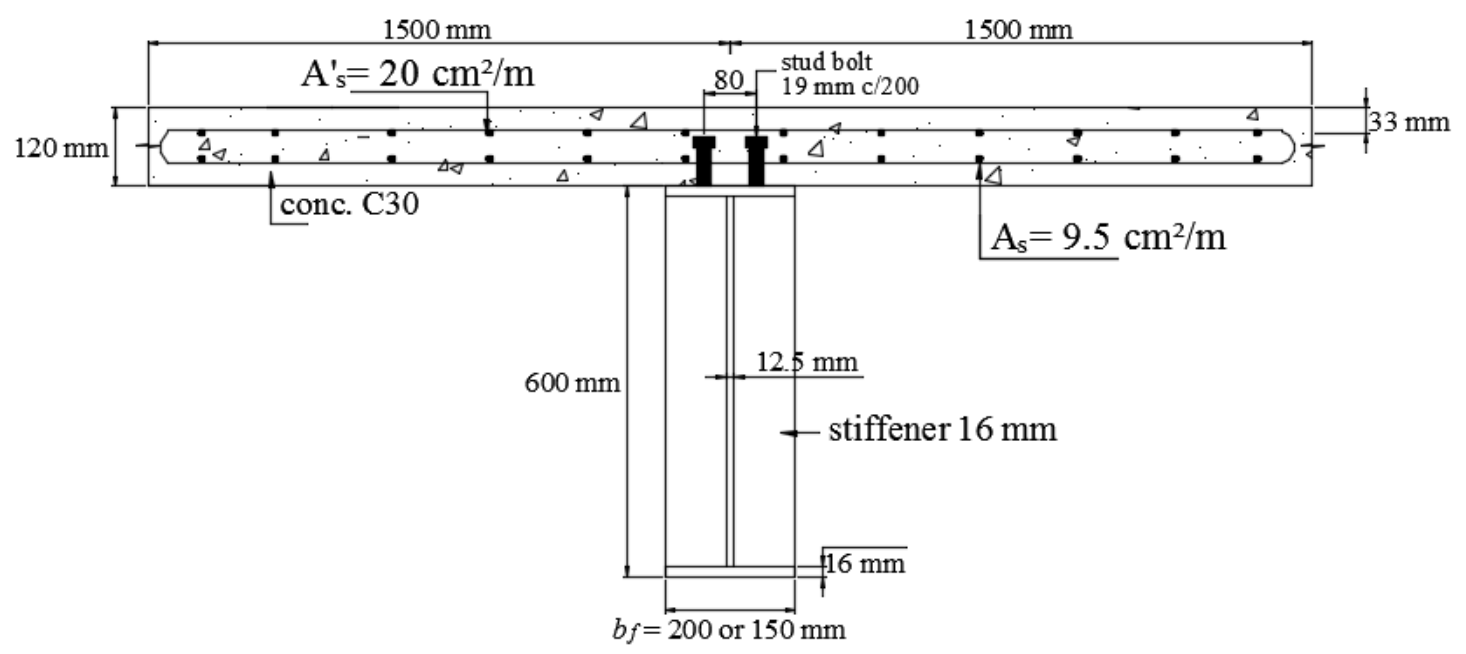

Figure 10. Cross section of the reference numerical model in the internal supports' region.

The mechanical properties of the materials were taken as the same in all analyzed numerical models. The elasticity modulus adopted for steel and concrete were equal to 200,000 MPa and 30,672 MPa, respectively. The Poisson's ratio was equal to 0.30 for steel and 0.2 for concrete. The yield strengths of the steel profile, shear connectors and reinforcement were equal to $300 \mathrm{MPa}, 345 \mathrm{MPa}$ and $500 \mathrm{MPa}$, respectively. Lastly, the compressive strength of concrete was adopted as $30 \mathrm{MPa}$.

\subsection{Parametric models}

An analysis of the influence on the lateral-torsional buckling of the transverse stiffeners positioned along the hogging moment region was performed. For this purpose, the numerical models MR1 and MR2 were initially used, which represent continuous composite beams with two spans (extreme span) subjected to uniformly distributed load without transverse stiffeners, with MR1 flange width equal to $150 \mathrm{~mm}$ and, MR2, $200 \mathrm{~mm}$. Then, stiffeners were added in the hogging moment region to these models, with the ratio between the spacing between them, $a$, and the height of the steel profile, $d$, equal to $0.625,1.041,1.25,1.5625,2.08$ and 3.125, as shown in Table 3, thus creating models ME1 to ME12. The height and thickness of the web of the steel profile adopted were chosen in order to have a profile that was classified as compact by the Brazilian standard [2] and as Class 3 by European standard [3], situation where the difference between both standards is greater. Then, models MR3 and MR4 were used as reference, without transverse stiffeners, to represent the case of a composite beam with three equal spans (inner span) subjected to uniform hogging bending moment at the central span (the two extreme spans were subjected to a uniformly distributed load), with flange widths of $150 \mathrm{~mm}$ in model MR3 and of 200 $\mathrm{mm}$ in MR4. In these models, the a/d ratio was also varied, as previously described, creating models ME13 to ME24. 
Table 3. Numerical models for analyzing the stiffeners influence.

\begin{tabular}{|c|c|c|c|c|c|c|}
\hline Model & Number of spans & $d(\mathrm{~mm})$ & $b_{f}(\mathbf{m m})$ & $t_{f}(\mathrm{~mm})$ & $t_{w}(\mathrm{~mm})$ & $a / d$ \\
\hline ME1 & 2 & 600 & 150 & 16 & 12.5 & 0.625 \\
\hline ME2 & 2 & 600 & 150 & 16 & 12.5 & 1.041 \\
\hline ME3 & 2 & 600 & 150 & 16 & 12.5 & 1.25 \\
\hline ME4 & 2 & 600 & 150 & 16 & 12.5 & 1.5625 \\
\hline ME5 & 2 & 600 & 150 & 16 & 12.5 & 2.08 \\
\hline ME6 & 2 & 600 & 150 & 16 & 12.5 & 3.125 \\
\hline MR1 & 2 & 600 & 150 & 16 & 12.5 & - \\
\hline ME7 & 2 & 600 & 200 & 16 & 12.5 & 0.625 \\
\hline ME8 & 2 & 600 & 200 & 16 & 12.5 & 1.041 \\
\hline ME9 & 2 & 600 & 200 & 16 & 12.5 & 1.25 \\
\hline ME10 & 2 & 600 & 200 & 16 & 12.5 & 1.5625 \\
\hline ME11 & 2 & 600 & 200 & 16 & 12.5 & 2.08 \\
\hline ME12 & 2 & 600 & 200 & 16 & 12.5 & 3.125 \\
\hline MR2 & 2 & 600 & 200 & 16 & 12.5 & - \\
\hline ME13 & 3 & 600 & 150 & 16 & 12.5 & 0.625 \\
\hline ME14 & 3 & 600 & 150 & 16 & 12.5 & 1.041 \\
\hline ME15 & 3 & 600 & 150 & 16 & 12.5 & 1.25 \\
\hline ME16 & 3 & 600 & 150 & 16 & 12.5 & 1.5625 \\
\hline ME17 & 3 & 600 & 150 & 16 & 12.5 & 2.08 \\
\hline ME18 & 3 & 600 & 150 & 16 & 12.5 & 3.125 \\
\hline MR3 & 3 & 600 & 150 & 16 & 12.5 & - \\
\hline M19 & 3 & 600 & 200 & 16 & 12.5 & 0.625 \\
\hline M20 & 3 & 600 & 200 & 16 & 12.5 & 1.041 \\
\hline M21 & 3 & 600 & 200 & 16 & 12.5 & 1.25 \\
\hline M22 & 3 & 600 & 200 & 16 & 12.5 & 1.5625 \\
\hline M23 & 3 & 600 & 200 & 16 & 12.5 & 2.08 \\
\hline M24 & 3 & 600 & 200 & 16 & 12.5 & 3.125 \\
\hline MR4 & 3 & 600 & 200 & 16 & 12.5 & - \\
\hline
\end{tabular}

The adoption of values of $150 \mathrm{~mm}$ and $200 \mathrm{~mm}$ for the flange width aimed to consider the influence of this dimension. Additionally, it is noteworthy that these two values are within a proportion usually adopted in composite beams, that is, between $1 / 4$ and $1 / 3$ of height of the steel profile and within the limit for the section to be classified as compact by Brazilian standard [2] and as Class 1 by European standard [3].

\section{ANALYSIS OF RESULTS}

Table 4 shows the plastic moment for each section for the analyzed numerical model, $M_{P l}^{-}$, obtained considering the steel profile and longitudinal reinforcement in the support section. There are also the results obtained numerically for the nominal resistant bending moment to LTB, $M_{d i s t, R k, n u m}^{-}$, and the results obtained analytically from the nominal bending moment to LTB, considering the procedure of the European standard [3], $M_{\text {dist,Rk,Eurocode }}^{-}$, and the procedure of the Brazilian standard [2], $M_{d i s t, R k, A B N T}^{-}$, both adopting Equation 8, proposed by Chen and Wang [15] for the calculation of the web's rotational stiffness. For the $M_{\text {dist }, R k, \text { Eurocode }}^{-}$calculation procedure, the steps mentioned in subsection 1.3 were adopted, considering the elastic critical moment, $M_{c r}$, proposed by Roik et al. [5]. The ratio between the LTB resistant moment of the analyzed model and the model taken as reference is also shown in this table. In the case of models ME1 to ME6, model MR1 is used as reference model (without stiffeners along the hogging moment region) and, for models ME7 to ME12, model MR2 was the reference. For the models ME13 to ME18, the reference model is MR3 and, lastly, for models ME19 to ME24, the reference model is MR4. Furthermore, the ratios between the numerical nominal resistant bending moment to LTB, $M_{\text {dist }, R k, \text { num }}^{-}$, and the analytical bending moment obtained according to the European standard [3], $M_{\text {dist }, R k, \text { Eurocode }}^{-}$, and Brazilian standard [2], $M_{\text {dist }, R k, A B N T}^{-}$are presented. 
Table 4. Results obtained for the analysis of the transverse stiffeners influence.

\begin{tabular}{|c|c|c|c|c|c|c|c|}
\hline Model & $\begin{array}{c}M_{p l}^{-} \\
(\mathbf{k N} \cdot \mathbf{m})\end{array}$ & $\begin{array}{l}M_{\text {dist }, R k, \text { num }}^{-} \\
(\mathbf{k N} \cdot \mathbf{m})\end{array}$ & $\begin{array}{l}M_{\text {dist }, R k, \text { num }, \text { current }}^{-} / \\
M_{\text {dist }, R k, \text { num }, \text { reference }}^{-}\end{array}$ & $\begin{array}{c}M_{\text {dist }, R k, \text { Eurocode }}^{-} \\
(\mathbf{k N} \cdot \mathbf{m})\end{array}$ & $\begin{array}{c}M_{\text {dist }, R k, A B N T}^{-} \\
(\mathbf{k N} \cdot \mathbf{m})\end{array}$ & $\begin{array}{c}M_{\text {dist }, \text { Rk,Eurocode }}^{-} / \\
M_{\text {dist }, \text { Rk, num }}^{-}\end{array}$ & $\begin{array}{c}M_{\text {dist }, R k, A B N T}^{-} / \\
M_{\text {dist }, R k, \text { num }}^{-}\end{array}$ \\
\hline ME1 & \multirow{7}{*}{1,205} & 1,147 & 1.15 & 787 & 1,151 & 0.69 & 1.00 \\
\hline ME2 & & 1,129 & 1.13 & 787 & 1,149 & 0.70 & 1.02 \\
\hline ME3 & & 1,118 & 1.12 & 787 & 1,148 & 0.70 & 1.03 \\
\hline ME4 & & 1,107 & 1.11 & 787 & 1,147 & 0.71 & 1.04 \\
\hline ME5 & & 1,104 & 1.10 & 787 & 1,145 & 0.71 & 1.04 \\
\hline ME6 & & 1,085 & 1.09 & 787 & 1,142 & 0.73 & 1.05 \\
\hline MR1 & & 1,000 & 1.00 & 769 & 1,072 & 0.77 & 1.07 \\
\hline \multicolumn{6}{|c|}{ average } & 0.72 & 1.04 \\
\hline ME7 & \multirow{7}{*}{1,345} & 1,324 & 1.09 & 921 & 1,302 & 0.70 & 0.98 \\
\hline ME8 & & 1,308 & 1.07 & 921 & 1,301 & 0.70 & 0.99 \\
\hline ME9 & & 1,288 & 1.06 & 921 & 1,300 & 0.72 & 1.01 \\
\hline ME10 & & 1,306 & 1.07 & 921 & 1,299 & 0.71 & 0.99 \\
\hline ME11 & & 1,290 & 1.06 & 921 & 1,298 & 0.71 & 1.01 \\
\hline ME12 & & 1,267 & 1.04 & 921 & 1,297 & 0.73 & 1.02 \\
\hline MR2 & & 1,220 & 1.00 & 921 & 1,238 & 0.75 & 1.01 \\
\hline \multicolumn{6}{|c|}{ average } & 0.72 & 1.00 \\
\hline ME13 & \multirow{7}{*}{1,325} & 1,155 & 1.47 & 671 & 1,057 & 0.58 & 0.92 \\
\hline ME14 & & 1,136 & 1.44 & 665 & 1,049 & 0.59 & 0.92 \\
\hline ME15 & & 1,093 & 1.39 & 663 & 1,045 & 0.61 & 0.96 \\
\hline ME16 & & 1,079 & 1.37 & 658 & 1,040 & 0.61 & 0.96 \\
\hline ME17 & & 1,026 & 1.30 & 652 & 1,031 & 0.64 & 1.00 \\
\hline ME18 & & 1,023 & 1.30 & 641 & 1,015 & 0.63 & 0.99 \\
\hline MR3 & & 787 & 1.00 & 477 & 744 & 0.61 & 0.95 \\
\hline \multicolumn{6}{|c|}{ average } & 0.61 & 0.96 \\
\hline ME19 & \multirow{7}{*}{1,465} & 1,318 & 1.31 & 841 & 1,246 & 0.64 & 0.95 \\
\hline ME20 & & 1,308 & 1.30 & 838 & 1,243 & 0.64 & 0.95 \\
\hline ME21 & & 1,294 & 1.29 & 836 & 1,241 & 0.65 & 0.96 \\
\hline ME22 & & 1,285 & 1.28 & 834 & 1,239 & 0.65 & 0.96 \\
\hline ME23 & & 1,251 & 1.25 & 831 & 1,235 & 0.66 & 0.99 \\
\hline ME24 & & 1,242 & 1.24 & 824 & 1,228 & 0.66 & 0.99 \\
\hline MR4 & & 1,004 & 1.00 & 622 & 955 & 0.62 & 0.95 \\
\hline \multicolumn{6}{|c|}{ average } & 0.65 & 0.96 \\
\hline \multicolumn{6}{|c|}{ global average } & 0.67 & 0.99 \\
\hline
\end{tabular}

The results of the numerical analysis indicate that the use of stiffeners in the hogging moment region, as expected, can provide a significant increase in the value of the resistant moment to LTB. Also, as expected, this increase is grater with the shortest spacing between the stiffeners and with the greatest difference between the value of the resistant moment of composite beam without stiffeners and the plastic moment of the cross section of the composite beam in the hogging moment. In the cases treated in this paper, the smallest increase was of $4 \%$, in model ME12, in which the spacing between the stiffeners was the maximum adopted $(a / d=3.125)$ and the ratio $M_{p l}^{-} / M_{d i s t, R k, n u m}^{-}$was the smallest in the beam without stiffeners $(1,345 / 1,220=1.10)$. In turn, the biggest increase was of $47 \%$, in model ME13, in which the spacing between the stiffeners was the minimum adopted $(a / d=0.625)$ and the ratio $M_{p l}^{-} / M_{d i s t, R k, \text { num }}^{-}$was the largest in the beam without stiffeners $(1,325 / 787=1.68)$.

Regarding the results of the resistant bending moment obtained with the prescriptions of the standards, it is observed that, by the European standard [3], the ratio between the obtained moment and the numerical one was between 0.58 and 
0.77, with overall average of 0.67. By the Brazilian standard [2], that ratio was between 0.92 and 1.05, with overall average of 0.99 . It is worth mentioning that, in both standards, $M_{c r}$ was calculated with Equation 1, proposed by Roik et al [5], and the web's rotational stiffness with Equation 8 for composite beams with transverse stiffeners, as recommended by Chen and Wang [15]. Thus, it is observed that the results obtained by the European standard [3] were very conservative and, as can be noted in Table 4, for models ME1 to ME5 and ME7 to ME12, there was no variation in the LTB resistant bending moment, since the factor $\chi_{\text {dist }}$ was always at the curve's plateau, with a maximum value equal to 1.0 .

The main reason why the resistant moment obtained by the European standard [3] is smaller than that obtained by the Brazilian standard [2] is due to the fact that the steel profiles are classified as Class 3 by the European standard [3], which limits the resistant moment to the moment corresponding to the beginning of yield, while, by Brazilian standard [2], the profiles are classified as compact and can reach the plastic moment. For the European standard [3], the web of the steel profile would be classified as Class 1 or Class 2 if the ratio between the height and thickness of the web were less or equal to 35.6. As the ratio obtained is 45.4, lower than 72.7 (upper limit for Class 3), the profile was classified as Class 3. The Brazilian standard [2] takes as parameter twice the height of the compressed part of the web divided by its thickness for profile classification (this ratio is equal to 84 for the profiles analyzed), with the upper limit for the section to be compact equal to 97.

Based on the above, it appears that the use of Brazilian standard [2] calculation procedure to obtain the LTB resistant moment of continuous steel and concrete composite beams with transverse stiffeners, determining the rotational stiffness of the web of the steel profiles through the equation proposed by Chen and Wang [15], Equation 8 presented in this paper, leads to good results. It can also be concluded that the use of this equation in conjunction with the Brazilian standard [2] led to better results than with the European standard [3], in beams where the steel profile is classified as compact by the first and as Class 3 by the second. Possibly, in cases where the steel profiles of the composite beams are Class 1 or 2 according to the European standard [3], the results obtained according to it will approximate those of the Brazilian standard [2].

Figure 11a shows the von Mises stress values when the resistant moment is reached in the steel profile of the model with a greater number of transverse stiffeners in the hogging moment region, ME7, as well as in Figure 11b for the model ME12 which has a smaller number of stiffeners in this region. It is possible to clearly observe that for these models, the yielded region was similar, regardless of the number of stiffeners in the hogging moment region. This confirms that the resistant gain is very low in relation to the composite beam without transverse stiffeners after adding transverse stiffeners in the hogging moment region in composite beams that present the resistant moment close to the plastic moment.

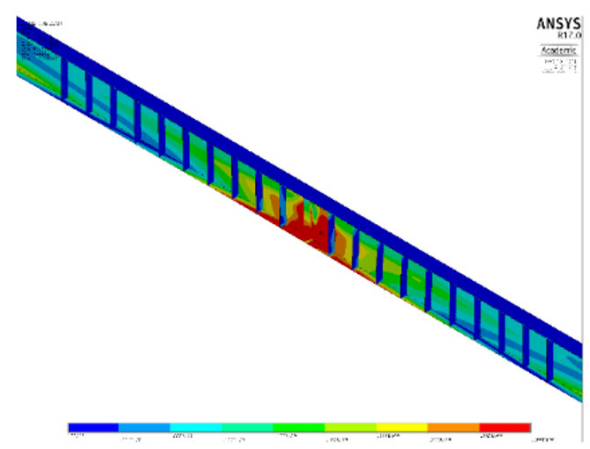

a) ME7 model

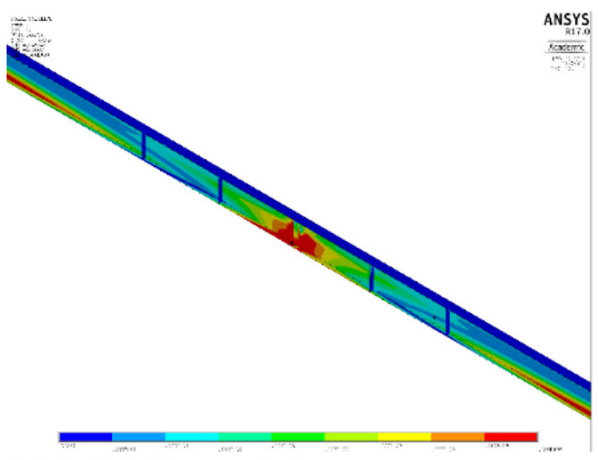

b) ME12 model

Figure 11. Von Mises stress in the steel profile of models ME7 and ME12.

As can be seen in Figure 12a, where von Mises stress values are also shown in the steel profile, the model with highest number of transverse stiffeners in the hogging moment region, ME13, presents a yielded region larger than that of the ME18 model, Figure 12b, which has a smaller number of stiffeners in this region, when the resistant moment is reached. It is worth mentioning that for these models, the gain in resistant capacity was much greater because the resistant moment for the case without stiffener is quite distant from the plastic moment of the composite beam. This demonstrates, once again, that by adding stiffeners in the hogging moment region, LTB becomes more difficult to 
occur, with plastification growing and the tendency for collapse to occur due to full plastification of the cross section, in a limit condition.

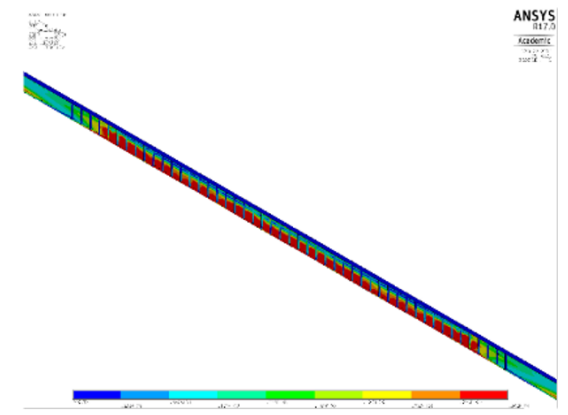

a) ME13 model

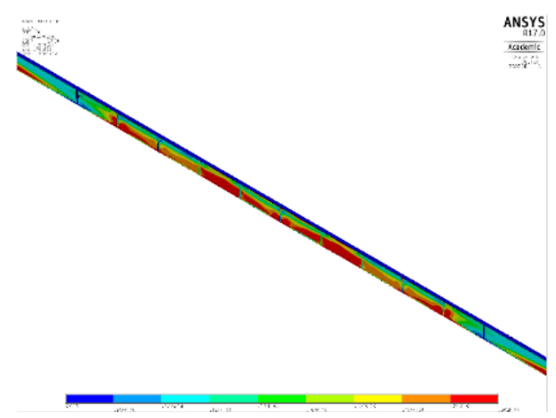

b) ME18 model

Figure 12. Von Mises stress in the steel profile of models ME13 and ME18.

The lateral displacements of the bottom flanges of numerical models MR2 (model without stiffener in the hogging moment region) and ME7 (model with stiffener) are shown in Figure 13a when the maximum moment is reached in the respective beams. The same is shown in Figure 13b for numerical models MR3 (model without stiffener) and ME13 (model with stiffener). It can be seen that for composite beams with identical cross sections, the beam with transverse stiffeners welded in the hogging moment region has a higher LTB resistant moment and has significantly reduced lateral displacement of the compressed flange in relation to the beam without stiffeners. It is thus observed that although the gain in value of the resistant bending moment in the ME7 model was small, of only 9\%, there was a considerable increase in the stiffness of the beam regarding the lateral displacement of the bottom flange, as shown in Figure 13a.

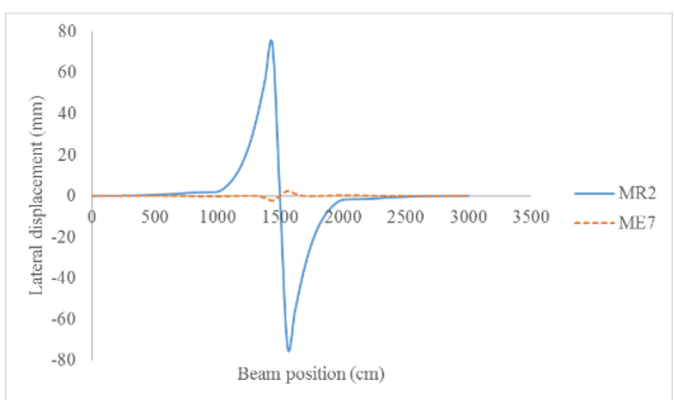

a) MR2 and ME7 models

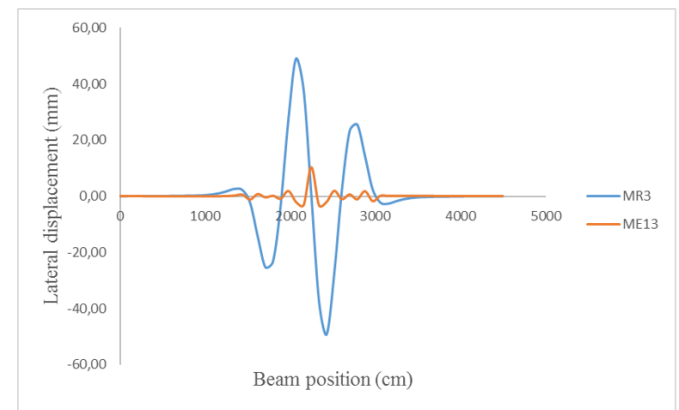

b) MR3 and ME13 models

Figure 13. Lateral displacement of the bottom flange of the steel profile.

\section{CONCLUSIONS}

In this paper, it was observed that the placement of transverse stiffeners regularly spaced in the hogging moment region of continuous composite beams increases the resistant moment, which was already expected. Is was also observed that this increase is greater, the smaller the spacing between stiffeners and the more distant the value of the resistant moment of composite beams without stiffeners to the plastic moment of the cross section of the composite beams in the hogging moment region, also as expected.

Composite beams with stiffeners in the hogging moment regions in which the steel profile is classified as compact by the Brazilian standard [2] and as a Class 3 by the European standard [3] were studied. In these beams, based on the results, it can be concluded that the method of calculation of the European standard [3] to obtain the moment resistant to LTB, using the elastic critical moment equation $\left(M_{c r}\right)$ of Roik et al. [5], Equation 1, and the expression of the rotational stiffness of the stiffened web presented by Chen and Wang [15], Equation 8, presents very conservative results, with overall average of 0.67 in relation to the moments obtained numerically. By the method of calculation of 
the Brazilian standard [2], with the rotational stiffness of the stiffened web obtained by Chen and Wang [15], the results obtained were closer to the numerical ones, with overall average of 0.99 in relation to the moments obtained numerically.

Therefore, from the presented study, it can be concluded that the resistant moment to LTB of continuous steel and concrete composite beams with compact steel profile and transverse stiffeners in the hogging moment region can be obtained with a good level of accuracy through the procedures described in the Brazilian standard [2], with the web's rotational stiffeness determined with Equation 8, presented by Chen and Wang [15].

\section{ACKNOWLEDGEMENTS}

The authors would like to acknowledge the support provided by the Brazilian public agencies Conselho Nacional de Desenvolvimento Científico e Tecnológico (CNPq), Coordenação de Aperfeiçoamento de Pessoal de Nível Superior (CAPES) and Fundação de Amparo à Pesquisa do Estado de Minas Gerais (FAPEMIG).

\section{REFERENCES}

[1] R. P. Johnson, Composite Structures of Steel and Concrete: Beams, Slabs, Columns and Frames for Buildings, 3rd ed. Warwick, U.K.: Blackwell, 2004.

[2] Associação Brasileira de Normas Técnicas, Projeto de Estruturas de Aço e de Estruturas Mistas de Aço e Concreto de Edificios, NBR 8800, 2008.

[3] European Committee for Standardization, Eurocode 4: Design of Composite Steel and Concrete Structures. Part 1-1: General Rules and Rules for Buildings, EN 1994-1-1, 2004.

[4] A. F. G. Calenzani, "Proposição de procedimento para a determinação da rigidez rotacional de vigas mistas contínuas e semicontínuas com perfis de alma senoidal,” Ph.D. dissertation, Progr. Pós-grad. Eng. Estrut., Univ. Fed. Minas Gerais, Belo Horizonte, 2008.

[5] K. Roik, G. Hanswille, and J. Kina, "Solution for the lateral torsional buckling problem of composite beams," Stahlbau, no. 59, pp. 327-332, 1990. [em alemão].

[6] M. A. Bradford and N. S. Trahair, "Distortional buckling of I-beams," J. Struct., vol. 107, pp. 355-370, 1981.

[7] S. E. Svensson, "Lateral buckling of beams analysed as elastically supported columns subject to a varying axial force," J. Construct. Steel Res., no. 5, pp. 179-193, 1985.

[8] P. Goltermann and S. E. Svensson, "Lateral distortional buckling: predicting elastic critical stress," J. Struct. Eng., vol. 114, no. 7, pp. $1606-1625,1988$.

[9] G. Hanswille, "Lateral torsional buckling of composite beams: comparison of more accurate method with Eurocode 4," Compos. Constr. Steel Concr., vol. IV, pp. 105-116, 2002.

[10] T. V. Amaral, J. P. S. Oliveira, A. F. G. Calenzani, and F. B. Teixeira, "Lateral-distorional buckling of continuous steel-concrete composite beam," Ibracon Struct. Mater. J., vol. 11, no. 4, pp. 719-756, 2018.

[11] J. V. F. Dias, J. P. S. Oliveira, A. F. G. Calenzani, and R. H. Fakury, "Elastic critical moment of lateral-distortional buckling of steelconcrete composite beams under uniform hogging moment," Int. J. Struct. Stab. Dyn., vol. 19, no. 7, pp. 1950079, 2019.

[12] J.P.S. Oliveira, "Nova proposição para verificação do estado-limite de flambagem lateral com distorção de vigas mistas de aço e concreto,” Ph.D. dissertation, Progr. Pós-grad. Eng. Estrut., Univ. Fed. Minas Gerais, Belo Horizonte, 2018.

[13] S. Chen, “Instability of composite beams in hogging bending,” Ph.D. dissertation, Dep. Eng., Univ. Warwick, 1992.

[14] A. F. G. Calenzani, R. H. Fakury, F. A. Paula, F. C. Rodrigues, G. Queiroz, and R. J. Pimenta, "Rotational stiffness of continuous composite beams with sinusoidal-web profiles for torsional buckling," J. Construct. Steel Res., vol. 79, pp. 22-33, 2012.

[15] S. Chen and X. Wang, "Finite element analysis of distortional lateral buckling of composite beams with transverse web stiffeners," Adv. Struct. Eng., vol. 15, no. 9, pp. 1607-1616, 2012.

[16] M. Z. Dietrich, A. F. G. Calenzani, and R. H. Fakury, "Analysis of rotational stiffness of steel-concrete composite beams for lateraltorsional buckling," Eng. Struct., vol. 198, 109554, 2019.

[17] Standard Association of Australia. Standard Association of New Zealand, Composite Structures - Composite Steel Concrete Construction in Buildings, AS/NZS 2327, 2017.

[18] Standards Association of Australia, Steel Structures, AS 4100, 1998.

[19] American Institute of Steel Construction, AISC Specifications for Structural Steel Buildings, ANSI/AISC 360-16, 2016.

[20] American Association of State and Highway Transportation Officials, AASHTO LRFD Bridge Design Specifications, 8th ed. with 2017 Interim Provisions. Washington: AASHTO, 2017. 
[21] A. Rossi, R. S. Nicoletti, A. S. C. Souza, and C. H. Martins, "Numerical assessment of lateral distortional buckling in steel-concrete composite beams," J. Construct. Steel Res., vol. 172, 106192, 2020.

[22] W. B. Zhou and W. J. Yan, "Refined nonlinear finite elemento modelling towards ultimate bending moment calculation for concrete composite beams under negative moment," Thin-walled Struct., vol. 116, pp. 201-211, 2017.

[23] Ansys, Inc., Release 17.0 Documentation for Ansys. Canonsburg, 2016.

[24] Associação Brasileira de Normas Técnicas, Projeto de Estruturas de Concreto - Procedimentos, NBR 6118, 2014.

[25] European Committee for Standardization, Eurocode 2: Design of Concrete Structures. Part 1-1: General Rules and Rules for Buildings, EN 1992-1-1, 2004.

[26] are R. Contamine, A. Si-Larbi, N. Q. Than, and P. Hamelin, "Numerical modeling of reinforced concrete beams under shear stress with and without external textile-reinforced concrete reinforcement," J. Reinf. Plast. Compos., vol. 30, no. 15, pp. 1293-1303, 2011.

[27] European Committee for Standardization, Eurocode 3: Design of Steel Structure. Part 1-5: Plated Structural Elements, EN 1993-1-5, Brussels, 2006.

[28] A. L. R. C. Silva, “Análise numérica não-linear da flambagem local de perfis de aço estrutural submetidos à compressão uniaxial,” Ph.D. dissertation, Progr. Pós-grad. Eng. Estrut., Univ. Fed. Minas Gerais, Belo Horizonte, 2006.

Authors contributions: JPSO: conceptualization, methodology, data processing and writing the paper; JVFD: conceptualization, formal analysis and general review; RHF: funding acquisition, supervision and general review; AFGC: formal analysis and general review.

Editors: Leandro Trautwein, Guilherme Aris Parsekian. 